\title{
QUALITY OF BUS SERVICES PERFORMANCE: BENEFITS OF REAL TIME PASSENGER INFORMATION SYSTEMS
}

\author{
Andres Monzon, Sara Hernandez, Rocio Cascajo \\ Transport Research Centre (TRANSyT), Universidad Politécnica de Madrid \\ C/Professor Aranguren s/n, 28040 Madrid, Spain \\ Ph.: +34 91 3365373. E-mail: andres.monzon@upm.es
}

\begin{abstract}
One of the main problems in urban areas is the steady growth in car ownership and traffic levels. Therefore, the challenge of sustainability is focused on a shift of the demand for mobility from cars to collective means of transport. For this purpose, buses are a key element of the public transport systems. In this respect Real Time Passenger Information (RTPI) systems help people change their travel behaviour towards more sustainable transport modes.

This paper provides an assessment methodology which evaluates how RTPI systems improve the quality of bus services performance in two European cities, Madrid and Bremerhaven. In the case of Madrid, bus punctuality has increased by $3 \%$. Regarding the travellers perception, Madrid raised its quality of service by $6 \%$ while Bremerhaven increased by $13 \%$. On the other hand, the users' perception of Public Transport (PT) image increased by $14 \%$.
\end{abstract}

Keywords: Real Time Information, bus reliability, perceived quality of service

\section{Introduction}

Today, negative externalities of mobility play a key role in transport policy. Current trends in transport indicate that the system is moving away from sustainability and the major changes are necessary to make the transport system more compatible with environmental sustainability [Banister et al., 2000]. Therefore, there is a need for new tools to achieve sustainable mobility in an efficient way.

The shape of the city and its transportation network set the mobility guidelines for a region [Monzon \& de la Hoz, 2009]. As a result of decentralization of the activities within the cities, one of the main problems in the urban areas is the steady growth in car ownership and traffic levels [Monzón et al., 2007]. This situation affects the everyday life of European people, while people need to move more rapidly between different places. The challenge of sustainability is facing calls for a shift of the demand for mobility from cars to collective means of transport. Hence, public transport performance has become a key issue, especially in urban areas. Particularly, bus systems are recognised as an essential component of efficient urban transport, providing a flexible and sustainable mode of transport [Hounsell et al., 2009].

Taking these circumstances into consideration, it is vital to increase the attractiveness of bus systems for all groups of stakeholders. The Intelligent Transport Systems (ITS) offer substantial potential for improving bus operations in urban areas, [Hounsell et al., 2009]. In recent years, the use of ITS in public transport has been widely extended. It includes systems which are installed in public transport vehicles as well as at terminals, stops and interchanges. An important part of these systems for public transport is to provide real time information to travellers with updated multimodal information about routes, departure times, possible disruptions and connecting services.

From the passengers' point of view, these measures are very useful for reducing the uncertainty of waiting time, which is very negatively weighted by PT users, and also for allowing an accessibility to all kind of information (fare, timetable, route, travel time, connections, etc.) for planning their journey, [Daskalakis \& Stathopoulos, 2008]. From the operator's point of view, these new technologies are very important for managing bus schedules, routes, incidents and thus improving the reliability and punctuality of the bus services.

This research study is based on the results of the European project "European Bus System of the Future", (EBSF) from the Seventh Framework Programme. The aim of this project is to develop a high quality bus system which combines, in an integrated way, innovations regarding vehicles, infrastructure and operation domains in order to create synergies, so that the value of the overall solution might be much higher than the simple addition of the value of each part. This project has tested some innovations in 7 European cities. 
The purpose of this research is to assess whether new technologies are providing a more attractive bus service and a better operation system, which can persuade car users to travel by bus, thus improving urban mobility thanks to this modal shift. In this paper we evaluate the impacts of new technologies on bus services performance and how Real Time Passenger Information (RTPI) systems could improve the perceived quality of services from the user's point of view. The methodology will be applied in two European cities, Madrid and Bremerhaven.

\section{Real Time Passenger Information Systems Applied to Bus Service Performance}

Bristow et al. (1997) in a global context and Tyrinopoulos and Antoniou (2008) in a domestic context highlight the importance of ITS applications for Public Transport (PT) attractiveness and their contribution towards improving the quality of services. There are several ITS applied to PT, depending on the desired purpose, e.g. Automatic Vehicle Location (AVL), Real Time Passenger Information (RTPI) both at bus stops and on board buses, Urban Traffic Control (UTC) and so on. From the passengers' point of view, supply of information is definitely the most important service ITS can offer [Politis et al., 2010].

It is widely accepted that RTPI offers significant benefits to PT users, present and potential, by providing a wide spectrum of information. In this respect RTPI systems improve PT services and help trip makers change their travel behaviour towards more sustainable transport modes, i.e., the reduction of car use contributing to road decongestion and, in general, to a more efficient transportation system. Therefore, the RTPI systems have been mainly developed to ease the use of PT through both perceived and actual reductions in passenger waiting time and increase passengers' satisfaction. Access to this information before the trip can assist in decreasing the actual waiting time, when information is available to the passenger on route; it can help to reduce the perceived waiting time [Daskalakis \& Stathopoulos, 2008].

Other likely benefits of the RTPI systems are as follows: increased willingness to pay; more efficient travelling through better use of waiting time; positive psychological effects such as reduced uncertainty, increased feeling of personal security, creation of a general sense of trust in the PT system, increased easiness of use; better overall image of the system; and greater passenger satisfaction. Several studies have dealt with these issues coming to similar conclusions that RTPI systems offer several benefits to PT users and that the majority of users are quite satisfied with them [Lappin, 2002; Tang \& Thakuriah, 2012]. Researches in this field have examined the potential effect of the introduction of RTPI systems on the perceived quality of service and bus services performance. Politis et al. (2010) evaluated a bus passenger information system from the users' point of view in the city of Thessaloniki, Greece. The analysis performed on the data collected from the survey of both regular and circumstantial PT users in the city showed that the existing RTPI system is generally evaluated positively. Satisfaction levels were quite high, over $80 \%$ for both - the content and the reliability of the information given [Politis et al., 2010]. Although extensive studies have been conducted on travel behaviour changes as a result of Information and Communications Technology (ICT), in general, studies of the nature in the case of real-time transit information systems are relatively few [Tang \& Thakuriah, 2012].

This study shows the results of the applications of innovative RTPI systems in two European cities. The analysis is focused on the user's perception and performance of advanced transport systems. The two cases highlight the importance of ITS tools to enhance the link among travellers, operators and regulators.

\section{Case Studies: Madrid and Bremerhaven}

As mentioned above, the two case studies selected for evaluating the impacts of innovative RTPI systems are Madrid and Bremerhaven. The following sections will describe the main characteristics of each case study.

\subsection{Madrid}

The Madrid case study is related to the metropolitan buses lines between the Majadahonda municipality and Madrid City, within the Madrid Region. The demand of bus services in the corridor, during a work day is 30,000 passengers (more than 50\% of the total users for the Majadahonda network). 

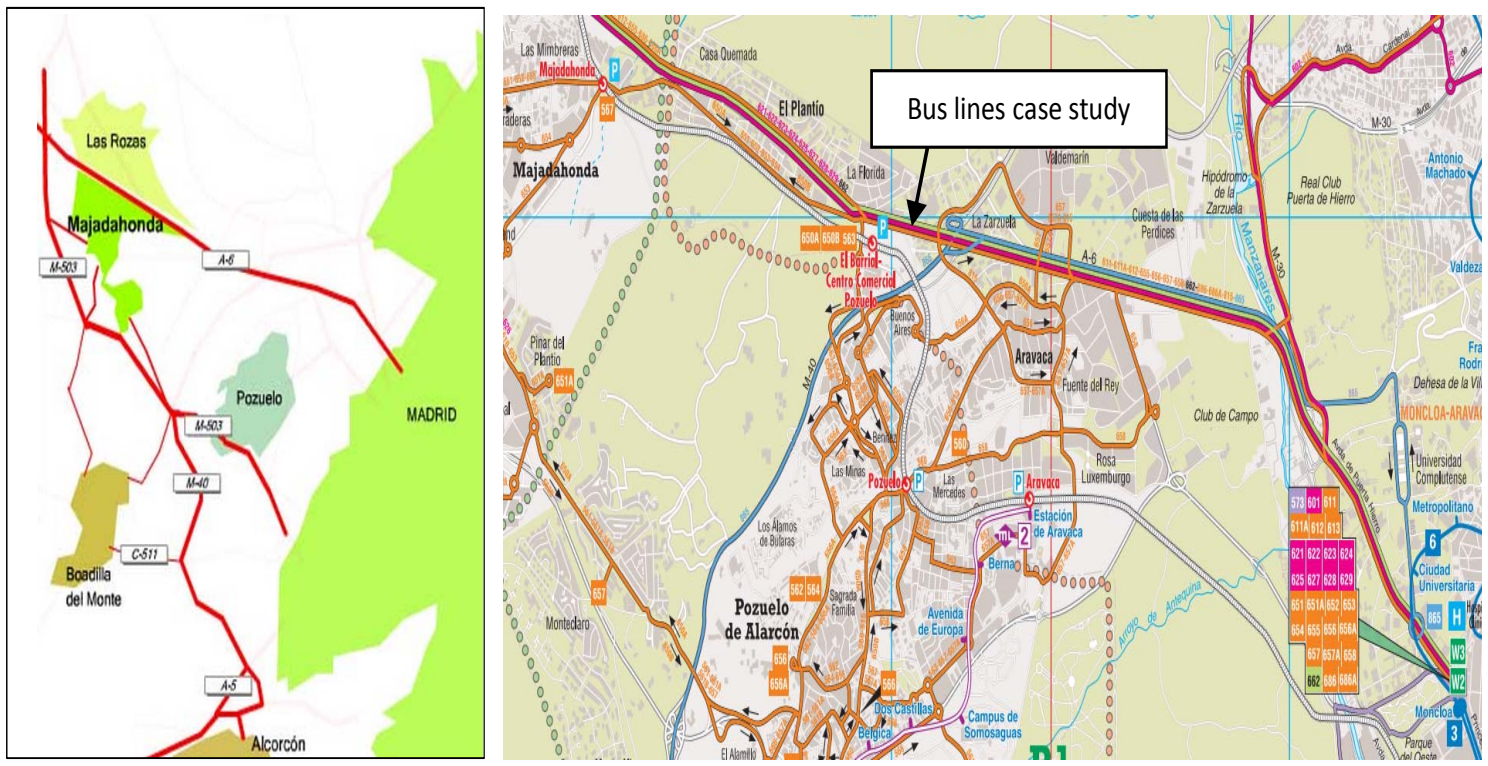

Figure 1. Majadahonda location and bus lines case study

Majadahonda is a town located in the west of Madrid, $18 \mathrm{~km}$ away from the centre of the capital. The municipality has an extension of $38.5 \mathrm{~km}^{2}$ and it has 70,000 inhabitants. The urban structure is summarized in a compact and small centre - the traditional city centre - to which are adhered many developments of single-family and multi-family residences of low density that extend across a large part of the municipality. There are only enclaves in which are tertiary activities concentrated, commercial and large equipments.

The public transport network in Majadahonda is composed of 18 intercity bus lines, 2 urban lines and a suburban rail station. Urban bus service is made up of circular lines 1 and 2. This is a unique circular route and each line runs in either direction. This service complements the service offered by intercity bus lines that pass through the city centre with alternative routes and that run through urban main streets. The main intercity bus to Madrid travels the corridor A-6, reaching the Moncloa interchange, in the capital. The approximate travel duration form Majadahonda to Moncloa Interchange is 30 minutes. Altogether, they constitute an important service with some 30,000 passengers on a working day. Regarding suburban rail station, it is well connected with urban and suburban bus lines. It is served by two suburban train lines connecting Majadahonda with 5 metropolitan interchangers and 8 connections with the underground network. The daily demand for the station is more than 10,000 passengers, including boarding and alighting passengers. The station has a park and ride facility of 1,200 places. The parking fees are applied to users of public transport according to their transport ticket (CRTM ${ }^{1}$ Travel $^{2}$ Pass, Monthly Travel Pass Cercanias and round trip tickets).

The main goals for the Madrid case study are related to technological and functional features needed to acquire multimodal dynamic information originated in different back office systems. In order to improve the quality of public transport services, encourage its use and provide the best mobility alternative, the main objectives of this case study are: 1) to improve the multimodal information offered to the user along the corridor, on board the vehicles, at stops and at the interchange station; 2) to support the advanced management of traffic for integrating all information, including PT information from interurban buses, regional train, metro and light rail networks, multimodal interchange station and road traffic information in order to have an overall knowing of all network and improving its management; and 3) to facilitate underground location of vehicles inside the interchange station.

It has been needed to develop and test architecture for a highly modular AVMS system. Such an integrator system in Madrid is called CITRAM (CRTM Integrated PT Management Centre).

\footnotetext{
${ }^{1}$ CRTM: Consorcio Regional de Transportes de Madrid (Public Transport Authority of the Madrid Region)
} 


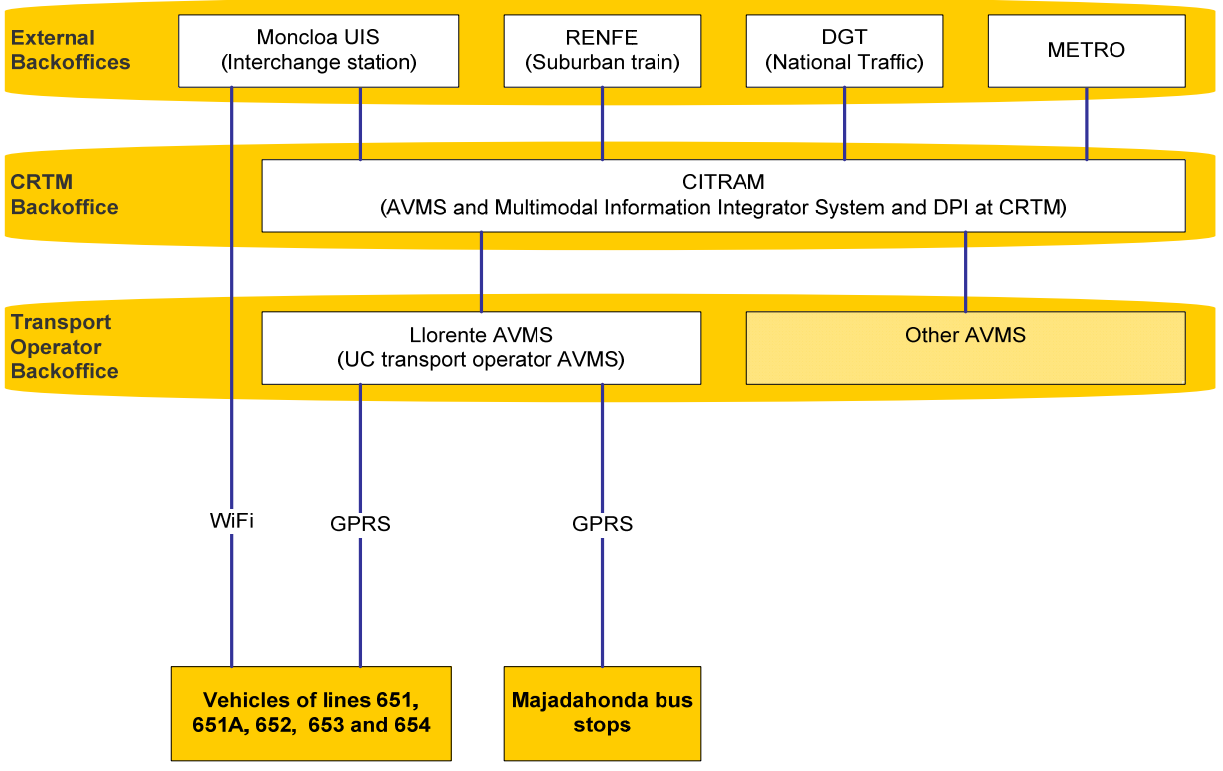

Figure 2. Madrid Use Case ITS system architecture

An advanced AVMS system has been implemented on 40 buses in 6 bus lines (651, 651A, 652, 653, 654 and 655) connecting Majadahonda and Moncloa interchange station, from September 2011 to February 2012. These buses were equipped with AVMS systems, including screens on board and audio information system. Four time-information displays (with audio system) were installed on bus stops in Majadahonda, plus one more with a Bluetooth device to download the information on next bus arrivals. One more screen was installed in Moncloa interchange to give next departures and breakdowns or delays.

In addition, a specific webpage was developed to provide real time information to the users. A SMS system was also deployed to get information about the next bus arrivals and incidents/ breakdowns on the whole transport network.

\subsection{Bremerhaven}

Bremerhaven is a city at the Weser delta at the German North Sea cost. It has about 114,000 inhabitants and is an exclave of the city state of Bremen. Bremerhaven has a thin, long geography (about $15 \mathrm{~km}$ long and $8 \mathrm{~km}$ wide, see Figure 3). There is a small city centre and the further inland fades out into less populated residential areas followed by rural areas for agriculture.

Public transportation consists only of buses, a fleet of 74 busses along 17 lines with a total of 253 bus stops. Due to the geographical situation of the city, stretched in North-South direction and bordered in the West by the river Weser and East by the neighbouring Federal State Lower Saxony, most of the lines are cross city dimensioned lines. In total the public transportation system serves 14.5 million passengers a year of which about two third are regular users (monthly tickets) and one fourth are students of the University and schools.

The main objective of the Bremerhaven case study is to increase attractiveness and availability of information for a large group of people in order to facilitate the shift from personal motorized transport to public transportation. This can be achieved by increasing comfort during the journey as well as during travel planning by providing the passengers with information with advanced IT and communication systems. It is also important to make PT available to more people by reducing physical constraints (e.g. for elderly people) as well as mental constraints (perception of security, reliability etc.) for using public transportation systems.

For this end, bus line 502 was selected as test field to encourage linkages between transfer points and surrounding areas and to extend the level of information to other means of transport and information sources. Line 502 runs through the whole city from north to south and covering about $65 \%$ of the entire city population. It serves in total 38 stops with an average distance between stops of about $400 \mathrm{~m}$ and an average commercial speed of $17.3 \mathrm{~km} /$ hour. All buses along line 502 are equipped with devices to get priority at most traffic lights and bus lanes at dedicated sections in the bus network. Furthermore at four bus stops are equipped with dynamic passenger information boards displaying the arrival time of each line stopping at that station. 

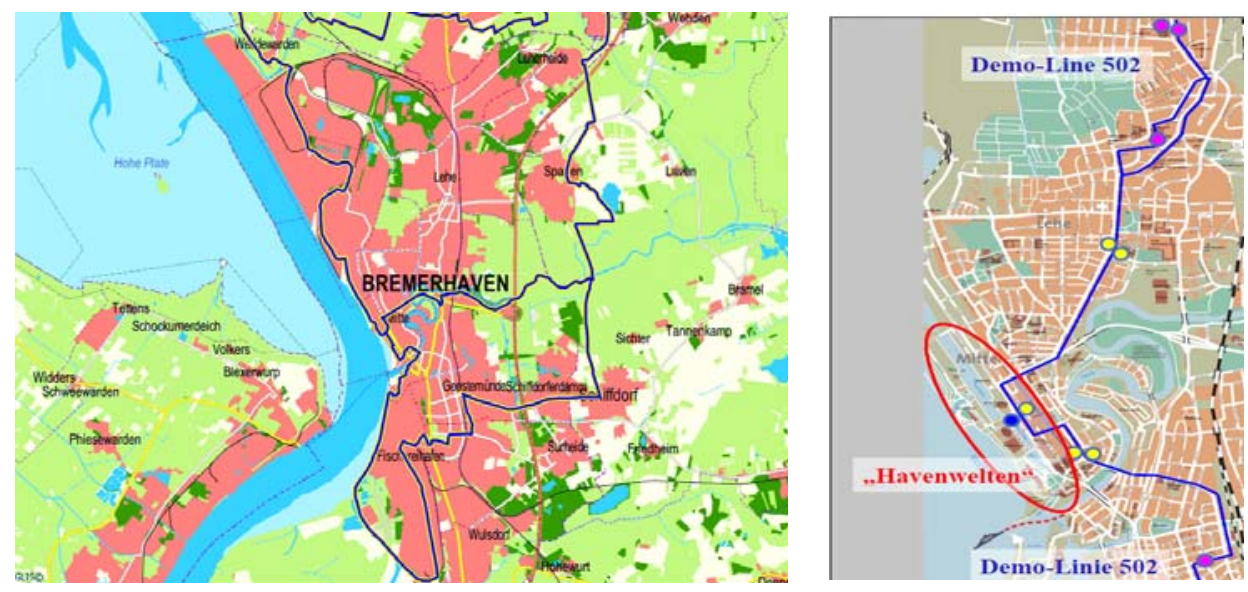

Figure 3. Map of Bremerhaven and surroundings

A vehicle of the type "EvoBus demonstrator" was equipped with a Driver Terminal and On-Board AVMS computer with integrated IP-Gateway functionality as well as announcement systems and TFT passenger information screens. The demo bus communicates with the central application via UMTS/GPRS, WLAN or LAN. All other busses serving line 502 were retrofitted with similar equipment. This system provided passengers with travel information during their trip. Furthermore, the main bus stops in the city centre are equipped with dynamic passenger information boards displaying the arrival time of each line stopping at that stop. Also all busses are supplied with a low floor access, for easy access to physically handicapped or elderly people.
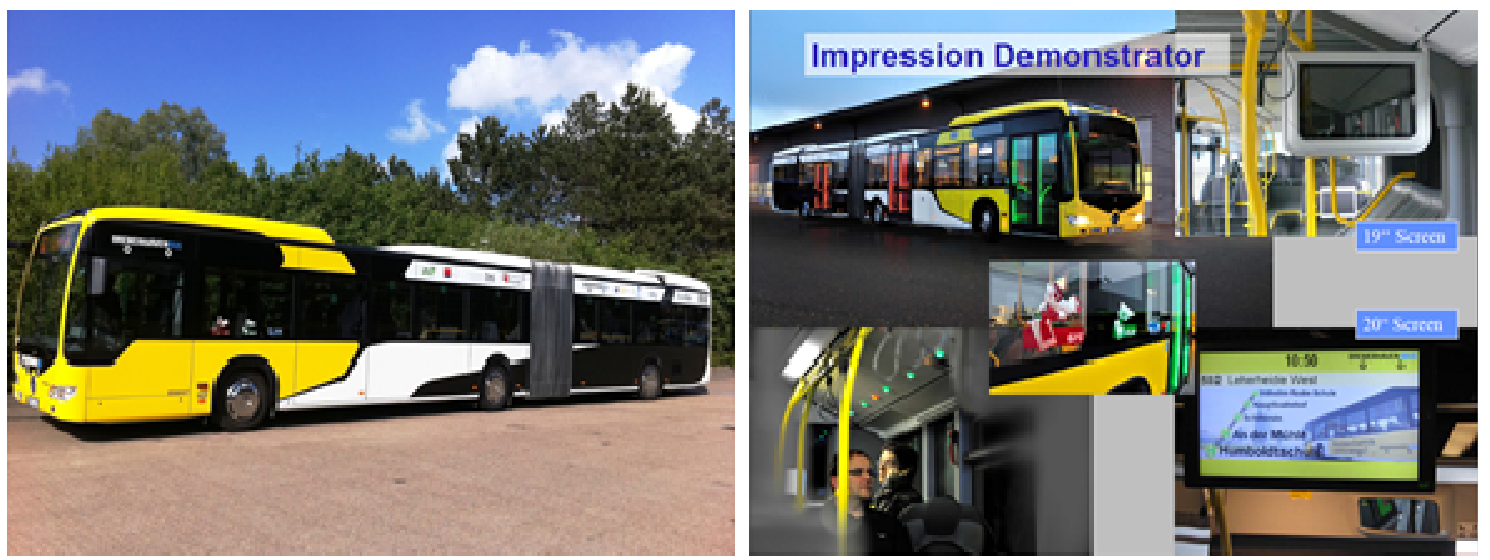

Figure 4. Bremerhaven EvoBus demonstrator and some equipment

\section{The Impacts of ITS Measures on Bus Performance}

The purpose of this study is to appraise the impacts of new technologies on quality of bus services performance. In order to achieve this purpose, an evaluation methodology was developed based on a previous research study about the evaluation of economic, social and environmental effects of urban transport projects [Cascajo, 2004]. The evaluation methodology aims to indicate up to what extent the implemented measures in the cases studies improve the following aspects of the bus systems:

- Customer satisfaction.

- Technical reliability.

- Cost-effectiveness.

- Externalities (environmental and social benefits). 
Considering both, the aspects to be improved and the main objectives of the EBSF project ${ }^{2}$, four evaluation categories were defined (see Figure 5). Implementation of the new technologies on bus system aims to improve image and increase attractiveness of bus system while at the same time it attempts to enhance the competitive position of bus manufacturers and operators. The four evaluation categories are:

- Quality of bus service.

- Customer satisfaction and attractiveness of bus services.

- Urban environment and social integration.

- $\quad$ Productivity of the bus systems.

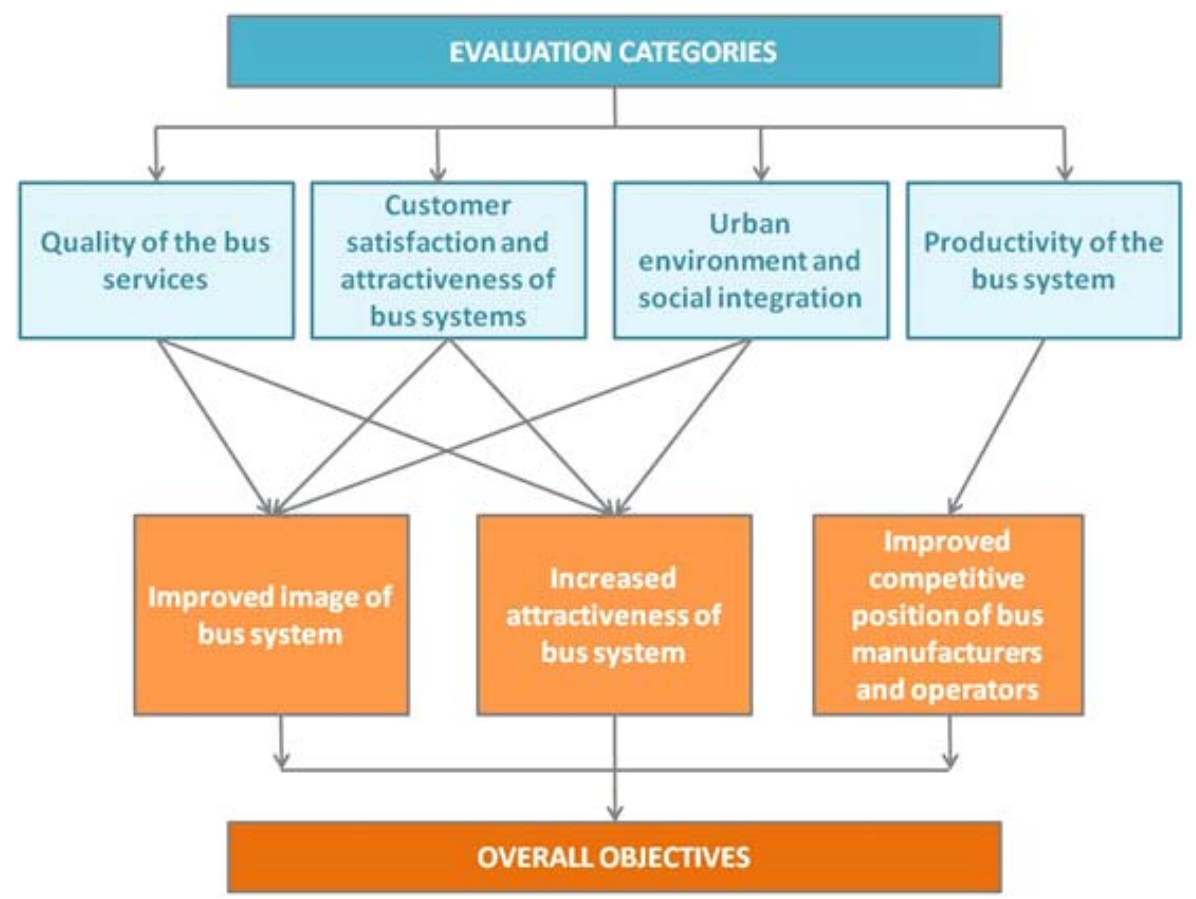

Figure 5. Direct and indirect relationship between the evaluation categories and the overall objectives

In order to measure how the evaluation categories are fulfilled two areas of investigation per category have been included (see Table 1).

Table 1. Evaluation categories and areas of investigation of the assessment

\begin{tabular}{|l|l|}
\hline \multicolumn{1}{|c|}{ Evaluation categories } & \multicolumn{1}{c|}{ Areas of investigation } \\
\hline \multirow{2}{*}{ Quality of the bus services } & Modal integration and additional/flexible services \\
\cline { 2 - 3 } Customer satisfaction and attractiveness of bus systems & Service performance \\
\hline \multirow{2}{*}{ Urban environment and social integration } & Comfort, cleanness and quality feeling/perception \\
\cline { 2 - 2 } & Information to passengers, relational and behavioural issues \\
\hline \multirow{2}{*}{ Productivity of the bus system } & Environmental issues \\
\cline { 2 - 2 } & Urban development and quality of life \\
\hline & Economic and operation issues \\
\cline { 2 - 2 } & Pricing and commercial policies \\
\hline
\end{tabular}

\footnotetext{
${ }^{2}$ The main objectives of the EBSF project are to: 1) develop an innovative, high quality, bus system which combines, an integrated way, innovations regarding vehicles, infrastructure and operation domains; 2) achieve a breakthrough design of vehicles, infrastructures and operations emphasising a system approach; and 3) maintain or improve the competitive position of the European bus manufacturers and operators worldwide, by promoting a new concept branded “The European Bus System”.
} 
For each evaluation category and area of investigation a set of Key Performance Indicators (KPIs) were selected [EBSF, 2012]. These areas of investigation are measured by assigning one or more KPIs.

To carry out the assessment of the performance two different scenarios are defined: "ex-ante" scenario (before the starting of the testing phase of each use case without any measure implemented) and "during" the testing phase (once the measures have been implemented). The analysis of the effects produced by a transport investment is based on the comparison between both scenarios. For quantitative KPIs, such as accessibility to real-time information or data on the number of stops equipped with realtime information, data collection was done before and after implementation. For the evaluation of the effectiveness and the public perception of the innovation (qualitative KPIs), passengers and operators had the opportunity to evaluate various categories with surveys and questionnaires during the two phases of inquiry: "Before" and "During". For qualitative KPIs, it was necessary to define a procedure to convert the qualitative results into a quantitative final score, in order to measure the variation between scenarios.

Table 2 shows the KPIs included in each area of investigation, the related unit of measurement and which KPI is measured in the case studies.

Table 2. Key Performance Indicators for the overall assessment

\begin{tabular}{|c|c|c|c|c|c|}
\hline Evaluation categories & Areas of investigation & KPIs & Units & MADRID & BREM \\
\hline \multirow{2}{*}{$\begin{array}{l}\text { Quality of the bus } \\
\text { services }\end{array}$} & $\begin{array}{l}\text { Modal integration and } \\
\text { additional/ flexible services }\end{array}$ & $\begin{array}{l}\text { Level of modal integration } \\
\text { services }\end{array}$ & $\%$ & $\mathrm{X}$ & \\
\hline & Service performance & Bus punctuality & $\%$ & $\mathrm{X}$ & \\
\hline \multirow{4}{*}{$\begin{array}{l}\text { Customer satisfaction } \\
\text { and attractiveness of } \\
\text { bus systems }\end{array}$} & \multirow{2}{*}{$\begin{array}{l}\text { Comfort, cleanness and quality } \\
\text { feeling/ perception }\end{array}$} & $\begin{array}{l}\text { Perceived quality of } \\
\text { services }\end{array}$ & $\begin{array}{l}\text { Rating of } \\
\text { quality }\end{array}$ & $\mathrm{X}$ & $\mathrm{X}$ \\
\hline & & $\begin{array}{l}\text { Customer perception of } \\
\text { image }\end{array}$ & $\begin{array}{l}\text { Rating of } \\
\text { image of bus } \\
\text { system }\end{array}$ & & $\mathrm{X}$ \\
\hline & \multirow{2}{*}{$\begin{array}{l}\text { Information to passengers, } \\
\text { relational and behavioural issues }\end{array}$} & $\begin{array}{l}\text { Accessibility of real time } \\
\text { passenger information }\end{array}$ & $\%$ & $\mathrm{X}$ & $\mathrm{X}$ \\
\hline & & $\begin{array}{l}\text { Availability of information } \\
\text { for connecting with other } \\
\text { PT services }\end{array}$ & $\begin{array}{l}\text { Rating of } \\
\text { availability }\end{array}$ & $\mathrm{X}$ & $\mathrm{X}$ \\
\hline \multirow{2}{*}{$\begin{array}{l}\text { Urban environment and } \\
\text { social integration }\end{array}$} & Environmental issues & Energy consumption & $\begin{array}{c}\text { Litres/ } \\
\text { pass-km }\end{array}$ & & $\mathrm{X}$ \\
\hline & $\begin{array}{l}\text { Urban development and quality } \\
\text { of life }\end{array}$ & Mobility of inhabitants & $\begin{array}{l}\text { Trips/ } \\
\text { inhabitants }\end{array}$ & $\mathrm{X}$ & \\
\hline \multirow{3}{*}{$\begin{array}{l}\text { Productivity of the } \\
\text { system }\end{array}$} & \multirow[b]{2}{*}{ Economic and operation issues } & Operating costs & Euro/km & & $\mathrm{X}$ \\
\hline & & Passenger demand & $\begin{array}{l}\text { Passenger/ } \\
\text { month }\end{array}$ & $\mathrm{X}$ & $\mathrm{X}$ \\
\hline & Pricing and commercial policies & Service efficiency & $\%$ & $\mathrm{X}$ & $\mathrm{X}$ \\
\hline
\end{tabular}

For the assessment of the performance of bus services in each case study, two kinds of evaluations will be carried out:

- Site specific evaluation, considering local conditions or particularities of the case studies, in which both, common and specific KPIs, are measured in each scenario. The results are analyzed site by site and for each KPI individually. The evaluation of the performance of each KPI is calculated as the relative variation between scenarios. Results are presented in Section 5.

- A cross-site evaluation is carried out in order to identify the most relevant factors in both cities and then see to what extent they contribute to the development of an innovative high quality bus system. For this evaluation, a Multicriteria Analysis (MCA) approach has been applied which will evaluate simultaneously the different criteria (areas of investigation) that need to be aggregated [EBSF, 2012]. The method consists in measuring each individual impact, and to aggregate all these values in a final single value. For this end it is necessary to carry out two steps; firstly, to convert the range of variation of each indicator to a homogeneous one, through utility functions; and, secondly, to assign a weight to each area of investigation to represent its relative importance for the development of an innovative high quality bus system. In order to achieve this purpose, it was necessary to conduct a specific survey among different stakeholders (operators, PT Authorities, manufacturers/industry, university/research centres) and users, 
from different countries. The final impact of the measures implemented, or social utility, is the weighted sum of all indicators. Figure 6 shows the scheme of the cross-site evaluation procedure.

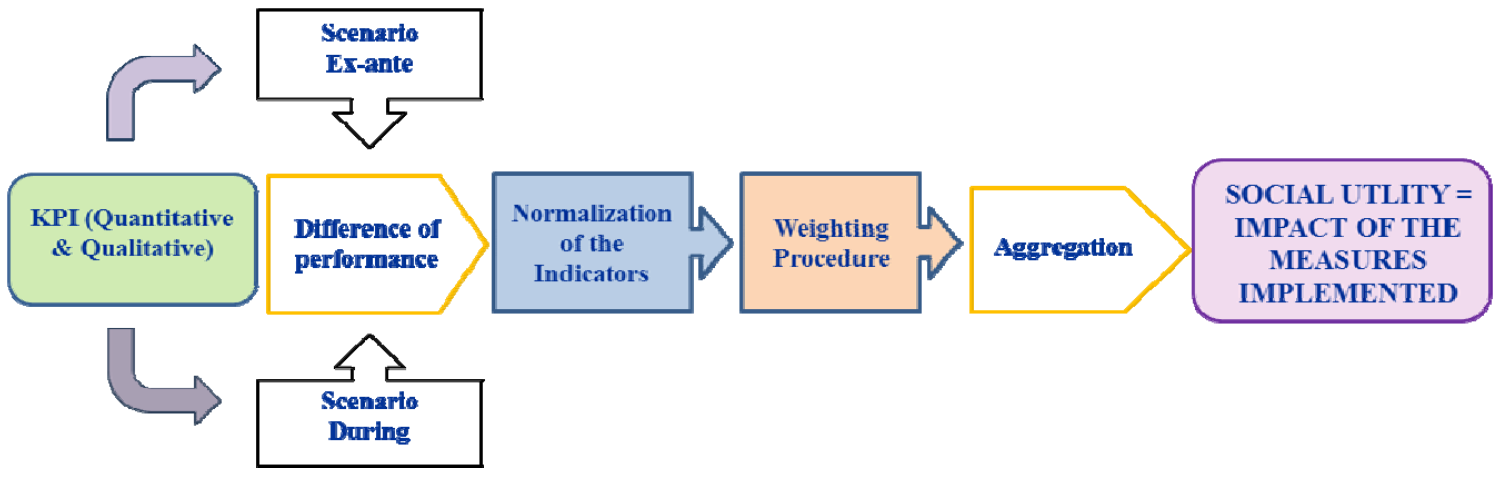

Figure 6. Cross-site evaluation procedure of the ITS measures applied to public transport systems

The formulation of the process can be written as an additive multiattribute function [Delle Site \& Filippi 2009]:

Social Utility $=\sum_{i=1}^{n} w_{i} \cdot \alpha_{i}$,

where $w_{i}$ is the weights and $\alpha_{i}$ the homogeneous values of each of the $n$ indicators.

The results are presented in Section 6.

\section{Site Specific Evaluation}

The site specific evaluation is a part of the overall assessment of the performance of the different measures implemented in the two cities: Madrid and Bremerhaven. This evaluation considers local conditions or particularities of each city.

\subsection{Madrid}

The evaluation was performed considering a set of 8 KPIs which allowed a comparison between the "before" and "during" test phases. The period of data collection was February 2011 for "ex-ante" data and February 2012 for "during” data. Information from the questionnaires, submitted to both Operator and Passengers, was collected between February and April 2011 (“ex-ante” data) and February 2012 ("during" data). The number of respondents on board the buses was 2,122 in "ex-ante phase and 2,234 in "during" phase, of which most of the passengers surveyed were female, 68\% against 32\% male. The $66.5 \%$ of the trips are carried out every weekday, and the ticket more used for this type of trip is the monthly ticket, $66.7 \%$. The results of the site specific evaluation are shown in Table 3.

Table 3. Madrid, KPIs values in each scenario and the variation

\begin{tabular}{|c|c|c|c|c|}
\hline Name KPI & Units/ Source & $\begin{array}{l}\text { Value } \\
\text { “ex-ante" }\end{array}$ & $\begin{array}{l}\text { Value } \\
\text { “during” }\end{array}$ & $\begin{array}{l}\text { Variation } \\
(\%)\end{array}$ \\
\hline Level of modal integration services & $\%$ & 74.5 & 72.7 & -2 \\
\hline Bus punctuality & $\%$ & 93.0 & 96.0 & 3 \\
\hline Perceived quality of service & $\begin{array}{l}\text { Rating of quality from } \\
\text { passenger's survey }\end{array}$ & 6.9 & 7.3 & 6 \\
\hline Accessibility of Real Time Passenger Information & $\%$ & 0 & 23.0 & 100 \\
\hline $\begin{array}{l}\text { Availability of information for connecting with other PT } \\
\text { services }\end{array}$ & $\begin{array}{l}\text { Rating of availability from } \\
\text { operators questionnaire }\end{array}$ & 5.90 & 7.10 & 20 \\
\hline Mobility of inhabitants & trips/ inhabitant & 3.6 & 3.8 & 6 \\
\hline Passenger demand & Passengers/month & $\begin{array}{r}507,0 \\
00\end{array}$ & $\begin{array}{r}457,0 \\
00\end{array}$ & -10 \\
\hline Service efficiency & $\%$ & 47.5 & 47.0 & -1 \\
\hline
\end{tabular}


According to Table 3, the level of modal integration services has decreased by $2 \%$ between scenarios. Although it is not a very significant variation, one reason for this was the decline in the monthly ticket sales, as a general trend in the whole public transport system in the Region, as a consequence of the decrease in demand due to the crisis and high rates of unemployment. This is proved in the KPI of passenger demand, which shows a decrease in the UC lines by $10 \%$. However, due to the availability of Real Time Passenger Information systems, a large number of aspects have improved in the bus operation. Bus punctuality increased by $3 \%$ with very high values of services in line with punctuality, 93\% and $96 \%$ respectively. Perceived quality of service by passengers rose by $6 \%$ for the ex-ante situation. The results obtained from the surveys to the operator show a $20 \%$ increase in the availability of information for connecting with other public transport services and mobility of inhabitants, in terms of number of trips per inhabitant, increased by 6\% (from 3.61 to 3.82 trips/inhabitant).

Concerning the perceived quality of service, passengers gave more value to punctuality, waiting time at bus stops and easiness of payment than to the possibility of getting information while travelling. The results are shown on Figure 7.

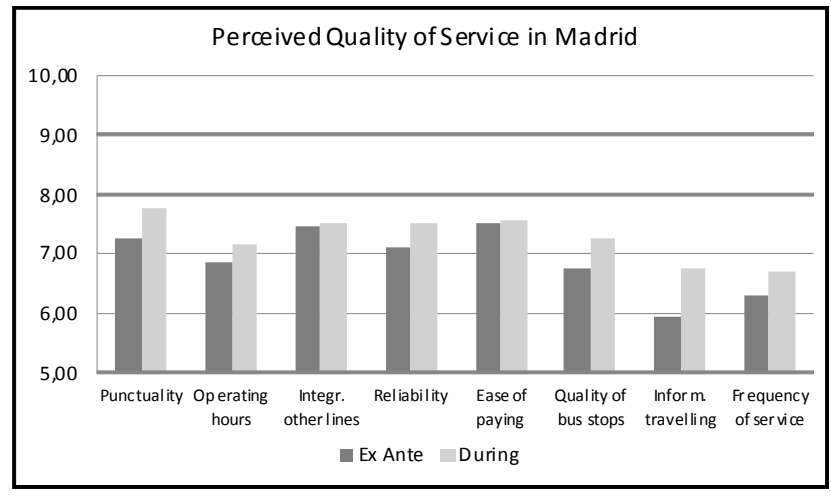

Figure 7. Aspects of the KPI perceived quality of service in Madrid

\subsection{Bremerhaven}

For the evaluation of the Bremerhaven case study, a set of 8 KPIs were defined. The period set for data collection was from July to September 2010 ("ex-ante”) and same months 2011 (“during”). Information from the questionnaires, submitted to both operator and passengers, was collected within this period. For the passenger survey 440 persons participated in the "ex ante" phase and 400 in the "during" phase. About $40 \%$ participants were male and $60 \%$ female; $76.8 \%$ of the participants use the bus line more than once a week, and $58 \%$ possess a long term ticket (monthly or yearly). The results obtained are shown in Table 4.

Table 4. Bremerhaven, KPIs values in each scenario and the variation

\begin{tabular}{|c|c|c|c|c|}
\hline Name KPI & Units/ Source & $\begin{array}{l}\text { Value } \\
\text { “ex-ante" }\end{array}$ & $\begin{array}{l}\text { Value } \\
\text { “during” }\end{array}$ & $\begin{array}{l}\text { Variation } \\
(\%)\end{array}$ \\
\hline Perceived quality of service & $\begin{array}{l}\text { Rating of quality from } \\
\text { passengers survey }\end{array}$ & 7.9 & 9.0 & 13 \\
\hline Customer perception of image & $\begin{array}{l}\text { Rating of image of bus system } \\
\text { from passengers survey }\end{array}$ & 7.5 & 8.7 & 14 \\
\hline Accessibility of real time passenger information & $\%$ & 47 & 52 & 11 \\
\hline $\begin{array}{l}\text { Availability of information for connecting to other PT } \\
\text { services }\end{array}$ & Passengers questionnaire & 8.0 & 8.3 & 2 \\
\hline Energy consumption & Litres / pass-km & $\begin{array}{r}0.093 \\
3\end{array}$ & $\begin{array}{r}0.095 \\
8\end{array}$ & -3 \\
\hline Operating costs & $€ / \mathrm{km}$ & 4.91 & 4.91 & 0 \\
\hline Passenger demand & Pass./month & $\begin{array}{r}248,6 \\
92\end{array}$ & $\begin{array}{r}239,7 \\
15\end{array}$ & -4 \\
\hline Service efficiency & $\%$ & 79 & 79 & 0 \\
\hline
\end{tabular}


In line with the general drop of the passenger demand between 2010 and 2011 on all lines in Bremerhaven, the passenger demand also decreased by $4 \%$ on line 502 . On the other hand, a small increase in fuel consumption (3\%) was recorded. According to the operator this was primarily attributed to higher use of air conditioning systems and electronic equipment. Nevertheless, several aspects improved thanks to the availability of Real Time Information Systems. Accessibility of real time information rose by $11 \%$ due to the installation of info-terminals on some stops as well as the availability of information for connecting to other PT services (2\%). Regarding passenger evaluation, it increased significantly in all relevant aspects in the "during" phase with respect to the "ex ante" phase. The perceived quality of service increased by $13 \%$ and the customer perception of image rose by $14 \%$.

Regarding the perceived quality of service, the ease of paying and the available information while travelling improve the passenger's perception of the service. Moreover, the image of the bus system improved through all aspects covered in the passenger survey. In particular, innovation was valued with $89 \%$ of possible score. This result indicates that the innovations were recognized and appreciated as an improvement of quality of service.

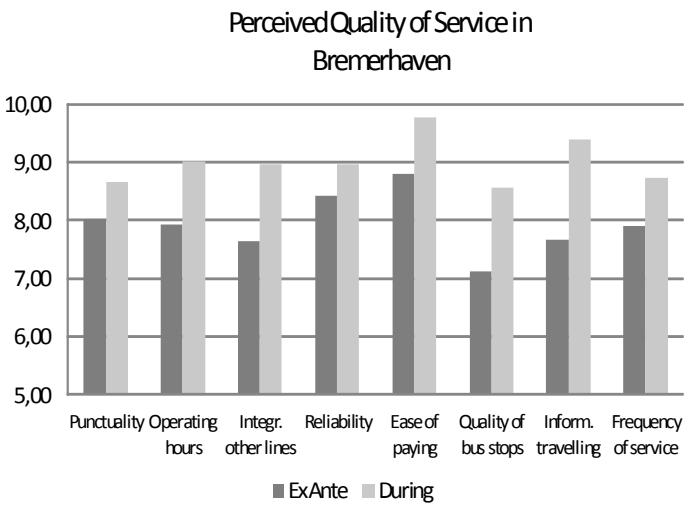

(a)
Perception of the Image of the Bus Systemin Bremerhaven

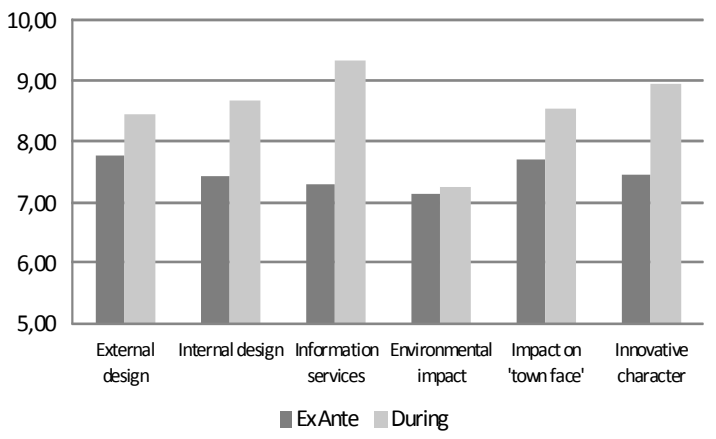

(b)

Figure 7. (a) aspects of the KPI perceived quality of services and (b) aspects of the KPI perception of the image of the bus system in Bremerhaven

\section{Cross-Site Evaluation}

A cross-site evaluation was carried out in order to identify the most relevant factors in both cities and to see to what extent they contribute to the development of an innovative high quality bus system.

As mentioned above, the measures were based on the Real Time Passenger Information systems implementation developed both in Madrid and Bremerhaven. When applying the evaluation procedure, Madrid presents higher social utility than Bremerhaven: 0.41 against 0.25 . In both cases, it can be observed that ITS measures implemented have a higher benefit mainly in the category "Customer satisfaction and attractiveness of bus systems".

Regarding "comfort, cleanness and quality feeling", passengers in Bremerhaven perceived an important increase in both, quality of service and image of the bus system. However, the improvement of this area of investigation in Madrid is due to the perception that passengers have experimented in punctuality, reliability, information while travelling and frequency.

According to the results of the surveys of passengers in the scenario "during", the overall satisfaction that passengers had with the service during the test was higher in Bremerhaven, with a score of 8.2 out of 10, while Madrid had 7.6.

Figure 8 shows the comparative results between the ex-ante and during scenarios for both cities. The user perception about all indicators improved with the implementation of RTPI systems. It is noticeable that some KPIs increase their score even when their real values remain the same. This means that the smarter the bus the more favourable perception of the users.

On the other hand, both cities present an impact in the area "information to passengers, relational and behavioural issues". Madrid improved the availability of information through different means (web, SMS, displays, Bluetooth, etc.); it is a multimodal information, providing the state of others modes of transport. In Bremerhaven, the equipment introduced in the retrofitted buses and the bus stops caused an increase in the quantity and quality of the real time information for passengers. 


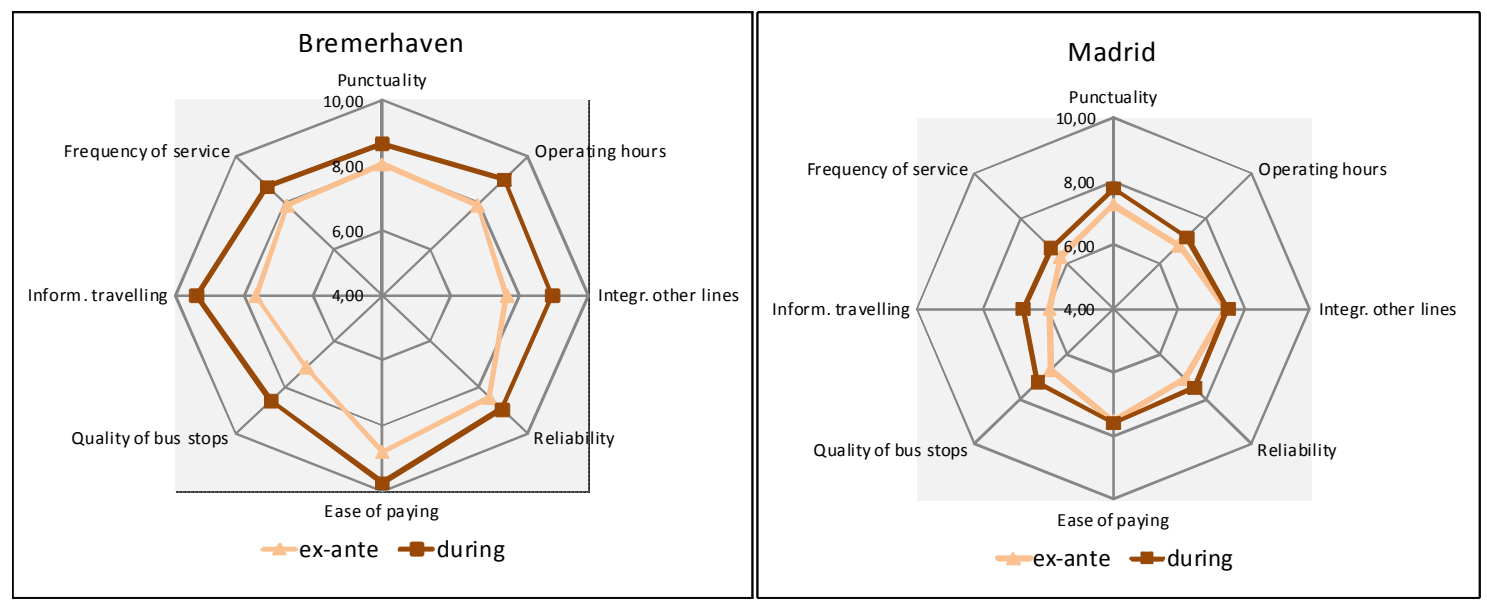

Figure 8. Cross-site evaluation of KPIs perceived quality of services

\section{Conclusions and Policy Recommendation}

The research results indicate the importance of providing bus services of high quality. For this purpose the use of RTPI systems appear to be a key factor. In both case studies the surveyed passengers showed a higher perceived quality of service when stops and buses are equipped with information devices.

In the case of Madrid, punctuality and reliability are two operational variables that improved thanks to the use of RTPI systems. Users are then more willing to use buses than before. The new information provided for connecting bus with other PT services clearly improve the seamless mobility in the corridor. These results can produce a transfer of trips from car to buses in the medium-long term.

The new prototype bus of Bremerhaven presents a high level of performance, which was very positively perceived by their users. It is remarkable that the perceived quality of service and the image increased by more than $13 \%$. Again this improvement of the level of service will attract passengers away from cars.

The methodology developed for assessing the customer satisfaction proved efficient to measure changes in the quality of bus services. Therefore, the proposed multi-criteria analysis could be valid for testing the impacts of new technologies in PT networks.

The overall results indicate the advantage of having a high level bus system. Most of the deterrent factors such as waiting time at stops, delays, uncertainty, payment time and lack of information for connecting with other services are clearly reduced. Hence, the image of PT became more competitive in relation with other modes, particularly cars. It produces environmental benefits because level of occupancy of buses is increased and the number of car trips reduced. In conclusion, it is very advisable to invest in a better bus fleet equipped with RTPI systems both on-board and at bus stops and terminals.

\section{References}

1. Banister, D., Stead, D., Steen, P., Akerman, J., Dreborg, K. \& Nijkamp, P. (2000). European transport policy and sustainable mobility. London: Spon Press.

2. Bristow, A., Pearman, A., \& Shires, J. (1997). An assessment of advanced transport telematics evaluation procedures. Transport Reviews, 17(3), 177-205.

3. Cascajo, R. (2004). Socio-environmental benefits of rail urban projects: A European benchmarking. In Proceedings of the European Transport Conference, 2004, 4-6 October. Strasbourg: ETC.

4. Daskalakis, N., \& Stathopoulos, A. (2008). Users' perceptive evaluation of bus arrival time deviations in stochastic networks. Journal of Public Transportation, 11(4), 25-38.

5. Delle Site, P., Filippi, F. (2009). Weighting methods in multi-attribute assessment of transport projects. European Transport Research Review, 1, 199-206.

6. $\quad$ EBSF. (2012). Evaluation report of use cases. (Deliverable 4.2.3 Ed.)

7. EBSF. (2008-2012). European Bus System of the Future. VII Framework Programme. European Commission. Retrieved $25^{\text {th }}$ September, 2012, from http://www.ebsf.eu/index.php/objectives 
8. Hounsell, N. B., Shrestha, B. P., Piao, J. \& McDonald, M. (2009). Review of urban traffic management and the impacts of new vehicle technologies. IET Intelligent Transport Systems, 3(4), 419-428.

9. Lappin, J. (2000). What have we learned about advanced traveler information systems and customer satisfaction? Chapter 4. In What have we learned about ITS? (pp. 66-85). Washington D.C.: Federal Highway Administration, U.S Department of Transportation.

10. Monzon, A., \& de la Hoz, D. (2009). Efectos sobre la movilidad de la dinámica territorial de Madrid. Urban, 14, 58-71.

11. Monzón, A., Pardeiro, A., \& Vega, L. (2007). Reducing car trip and pollutant emissions through strategic transport planning in Madrid, Spain. Highway and Urban Environment, 12(1), 81-90.

12. Politis, I., Papaioannou, P., Basbas, S. \& Dimitriadis, N. (2010). Evaluation of a bus passenger information system from the users' point of view in the city of Thessaloniki, Greece. Research in Transportation Economics, 29 (1), 249-255.

13. Tang, L., \& Thakuriah, P. (2012). Ridership effects of real-time bus information system: A case study in the city of Chicago. Transportation Research Part C: Emerging Technologies, 22(0), 146-161.

14. Tyrinopoulos, Y. \& Antoniou, C. (2008). Public transit user satisfaction: Variability and policy implications. Transport Policy, 15(4), 260-272. 